Fusi on neut ron producti on wi th deuter $i$ um neut $r$ al beaminjection and enhancement of energet i c- particle physics study in the Large Hel i cal Devi ce

\begin{tabular}{|l|l|}
\hline $\begin{array}{l}\text { j our nal or } \\
\text { publ i cat } \mathrm{i} \text { on } \mathrm{t} \text { i } \mathrm{tl} \text { e }\end{array}$ & Nucl ear Fusi on \\
\hline vol une & 58 \\
\hline number & 8 \\
\hline page $\mathrm{r}$ ange & 082004 \\
\hline year & 2018 - 06-29 \\
\hline URL & ht t p: //hdl . handl e. net /10655/00012710 \\
\hline
\end{tabular}




\title{
Fusion neutron production with deuterium neutral beam injection and enhancement of energetic-particle physics study in the Large Helical Device
}

\author{
M. Isobe ${ }^{1,2}$, K. Ogawa ${ }^{1,2}$, T. Nishitani ${ }^{1}$, N. Pu ${ }^{2}$, H. Kawase ${ }^{2}$, R. Seki ${ }^{1,2}$, H. Nuga ${ }^{1}$, \\ E. Takada ${ }^{3}$, S. Murakami ${ }^{4}$, Y. Suzuki ${ }^{1,2}$, M. Yokoyama ${ }^{1,2}$, M. Osakabe ${ }^{1,2}$, \\ and LHD Experiment Group ${ }^{1}$
}

${ }^{1}$ National Institute for Fusion Science, National Institutes of Natural Sciences Toki 509-5292, Japan

${ }^{2}$ SOKENDAI (The Graduate University for Advanced Studies), Toki 509-5292, Japan

${ }^{3}$ National Institute of Technology, Toyama College, Toyama 939-8630, Japan

${ }^{4}$ Kyoto University, Kyoto 615-8540, Japan

\begin{abstract}
The deuterium operation of the Large Helical Device (LHD) heliotron started in March 7, 2017, after longterm preparation and commissioning works necessary to execute the deuterium experiment. A comprehensive set of neutron diagnostics was implemented to accelerate energetic-particle physics research in the LHD. The calibrated ex-vessel neutron flux monitor indicated that the total neutron emission rate in the first deuterium campaign reached $3.3 \times 10^{15} \mathrm{n} / \mathrm{s}$ in inward shifted magnetic field configuration where confinement of helically trapped energetic ions is predicted to be better. Density dependence of measured total neutron emission rate was consistent with that predicted by the calculation. The neutron decay rate analysis following perpendicular deuterium beam blips injection suggested that the confinement of helically trapped beam ions can be understood by the classical slowing down model in relatively high-electron density plasmas at inward shifted magnetic field configuration. On the other hand, loss of helically-trapped beam ions was recognized even in the inward shifted configuration in the case of low density. Performance of the vertical neutron camera was verified by changing the plasma position and/or magnetic field strength. Drastic change of neutron emission profile was observed when the resistive interchange mode driven by helically-trapped beam ions appears. It was successfully demonstrated that the vertical neutron camera can play an important role in revealing radial transport and/or loss of beam ions. Triton burnup study was also conducted. In the first deuterium campaign, the maximum triton burnup ratio of $0.45 \%$ was obtained in inward shifted configuration. The burnup ratio decreased as a plasma was shifted outwardly as expected.
\end{abstract}




\section{Introduction}

In high-temperature deuterium and/or deuterium-tritium plasmas, fusion neutrons are generated due to d$\mathrm{d}$ and/or d-t fusion reaction. Fusion neutron has been one of the attractive objects for diagnosing the plasma performance in the history of nuclear fusion development. In the early days of fusion study, the measurement of the fusion neutrons was recognized as a fuel-ion temperature diagnostic. Around 1970, neutron spectrometry was proposed to evaluate fuel-ion temperature through the measurement of Doppler broadening of neutron energy $[1,2]$. In the mid-1970s, the fuel-ion temperature was evaluated from the total neutron emission rate $\left(S_{n}\right)$ measurements in small-sized tokamaks [3, 4] and was also assessed through neutron spectroscopy in the mid-1980s [5,6]. In parallel with the fuel-ion temperature measurements, as the deuterium neutral injection experiment progressed, the role of the neutron measurement shifted from being a fuel-ion temperature diagnostic to being an energetic-ion diagnostic in addition to fusion gain assessment because generated neutrons in deuterium neutral beam (NB)-heated deuterium plasmas are dominated by neutrons resulting from beam-plasma reactions [7, 8]. Deceleration of beam ions following NB turn-off was checked for the first time by measuring $S_{n}$ in the Princeton Large Torus [9]. Subsequently, a beam blip injection method was developed to enhance accuracy of analysis on slowing-down property on beam ions in tokamaks [10-12]. After that, a rapid drop of $S_{n}$ due to fishbone mode destabilized by perpendicularly-injected beam ions was found in the Poloidal Divertor Experiment [13]. It has been increasingly recognized that fusion neutron diagnostic can provide beneficial information of global behavior of energetic ions in tokamaks utilizing deuterium NB injections [14, 15]. Based on this background, diagnostics based upon nuclear technology have been steadily enhanced, in particular, in large tokamaks such as the Joint European Torus (JET) [16-18]. In the near future, neutron and gamma-ray diagnostics will play the leading role in assessing fusion output and/or energetic-ion confinement property in the International Thermonuclear Experiment Reactor [19-21].

Turning one's eyes to helical/stellarator devices, fusion neutron measurement was performed in Wendelstein 7-A for the first time in helical/stellarator devices. Then, the decay time of $S_{n}$ following NB turnoff was analyzed to check whether beam ions were decelerated classically without loss or not [22]. Subsequently, neutron emission rate and/or yield measurements were conducted in the Heliotron-E [23, 24], the Advanced Toroidal Facility [25], the Compact Helical System [26, 27], and the Wendelstein 7-AS [28, 29]. Because those devices were small- and/or medium-sized and their heating systems were not as intense, $S_{n}$ were very low, by about $10^{9} \sim 10^{10} \mathrm{n} / \mathrm{s}$. In such a case, the usage of neutron diagnostic was limited and was not very effective in studying confinement property of energetic ions. The helical plasma research entered a new stage on March 7, 2017. The deuterium operation began in the Large Helical Device (LHD), which is the world's largest-class helical device [30] in order to explore a higher-confinement plasma regime. One of the primary purposes of the LHD deuterium project is to demonstrate that confinement capability of energetic ions is relevant to the future burning plasma in helical systems. Note that energetic-ion physics studies such 
as ripple transport of beam ions [31-33], effect of toroidicity-induced Alfvén eigenmodes [34-36], energeticparticle continuum modes [37], resistive interchange modes [38] on beam ion loss, and effects of resonant magnetic perturbation field on beam ion loss [39] have been intensively conducted by using various energetic-particle diagnostics such as scintillator-based escaping energetic-ion diagnostic and chargeexchanged neutral particle analyzers [40] in the hydrogen operation phase in the LHD. Because these diagnostics do not provide directly information of energetic ions at core domain, we have concentrated on phenomenological and qualitative arguments regarding energetic ion's behavior. Since fusion neutron signals are newly available, the deuterium plasma experiment can provide an important opportunity to enhance energetic-particle physics study in the LHD. The LHD is capable of producing fusion neutrons over $1 \times 10^{16}$ $(\mathrm{n} / \mathrm{s})$, which is much higher than that observed in the small and medium class helical/stellarator devices. To extend energetic-particle physics study in the LHD, a comprehensive set of neutron diagnostics was prepared before the start of deuterium operation consisting of the neutron flux monitor (NFM), the neutron activation system (NAS), the vertical neutron camera (VNC), the neutron fluctuation diagnostic, and scintillating-fiber detectors for triton burnup. In this paper, hardware on neutron diagnostics prepared for the LHD deuterium operation is described. Also, representative measurement results obtained in the first deuterium campaign of the LHD are presented.

\section{Neutron generation in the LHD deuterium plasma}

LHD is the world largest-class helical device equipped with intense neutral beam heating facility of the 30 MW class. The first plasma was initiated in March 1998 with hydrogen gas and high $\beta$, high temperature, and steady-state operation capabilities have been demonstrated to date [41]. To explore achievable maximum performance of the LHD plasma, the deuterium operation began in March 2017. In a deuterium plasma, the following nuclear fusion reactions primarily occur.

$$
\begin{array}{ll}
\mathrm{d}+\mathrm{d} \rightarrow \mathrm{n}(2.45 \mathrm{MeV})+{ }^{3} \mathrm{He}(0.82 \mathrm{MeV}) & Q=3.27 \mathrm{MeV} \\
\mathrm{d}+\mathrm{d} \rightarrow \mathrm{p}(3.02 \mathrm{MeV})+\mathrm{t}(1.01 \mathrm{MeV}) & Q=4.03 \mathrm{MeV}
\end{array}
$$

Both $d-d$ reactions take place almost equally. In addition to these two reactions, triton generated by $d-d$ reaction will undergo secondary $\mathrm{t}-\mathrm{d}$ reaction producing ${ }^{4} \mathrm{He}(3.56 \mathrm{MeV})$ and neutron $(14.03 \mathrm{MeV})$ with background thermal deuterons. Tritons produced by $\mathrm{d}(\mathrm{d}, \mathrm{p}) \mathrm{t}$ reaction are isotropic in the velocity space. Also, kinematic parameters of $1 \mathrm{MeV}$ triton such as Larmor radius and precessional drift frequency are almost the same as those of d-t born alpha particles. Therefore, triton born in deuterium plasma has been often used in place of alpha particle.

The LHD is equipped with three negative-ion-source-based neutral beam (N-NB) injectors and two positive-ion-source-based neutral beam (P-NB) injectors as shown in Fig. 1. Energetic beam ion with injection energy $E_{b}$ of about $180 \mathrm{keV}$ is delivered by the three tangential N-NB injectors (\#1, 2, and 3). The $\mathrm{N}-\mathrm{NB}$ injection power in the first deuterium campaign was $\sim 2 \mathrm{MW}$ for each. Beam ions provided by the P- 
NB injectors are perpendicularly injected and the total injection power was $9 \mathrm{MW}$ with $E_{b}$ of $60 \mathrm{keV}$ to 80 $\mathrm{keV}$. Beam ions delivered by those neutral beam (NB) injectors play an essential role in generating fusion neutron in the LHD. Prior to the start of deuterium operation, expected $S_{n}$ in the LHD was calculated with velocity distribution function expressed by a steady-state Fokker-Planck equation. The calculation suggests that $S_{n}$ will exceed $1 \times 10^{16} \mathrm{n} / \mathrm{s}$ when full power NB heating is performed [30]. The maximum $S_{n}$ expected in the LHD deuterium plasma is almost comparable with that recorded in the deuterium operation of large tokamaks, e.g., the Tokamak Fusion Test Reactor (TFTR) [42] and the JAERI Tomakak-60U (JT-60U) [43].

\section{Neutron diagnostics prepared for the LHD deuterium operation}

To extend energetic-particle physics studies in the LHD, a comprehensive neutron diagnostic system was developed. The neutron diagnostics prepared for the first deuterium campaign of the LHD are listed in Table 1. The NFM is essential in the LHD operation in addition to physics purposes since annual neutron budget permitted by the Nuclear Regulation Authority of Japan is set to be $2.1 \times 10^{19}$. Therefore, the LHD cannot be operated without the NFM. Conceptual design of the LHD neutron diagnostics was performed before the initial operation of LHD [44]. Component technology test and/or development was initiated in around 2000 and a more concrete system was proposed subsequently [45]. As for the system development, we initiated development of a wide dynamic range NFM based on leading-edge digital technologies at the outset [46]. The NFM on LHD consists of three sets of two detectors as schematically depicted in Fig. 2(a). Each set has an ${ }^{235} \mathrm{U}$ fission chamber $(\mathrm{FC})$, and a ${ }^{10} \mathrm{~B}$ counter or a ${ }^{3} \mathrm{He}$ counter. The $\mathrm{FC}$ line can provide very wide dynamic range and fast-time response capabilities, and is designed so as to realize neutron pulse counting rate up to $5 \times 10^{9} \mathrm{cps}$. The FC line is responsible for middle- to high-neutron yield shots when NBs are injected. Other neutron counters can work for low-neutron yield shot such as electron cyclotron resonance heating (ECRH) shot without NB injection. Parallel to the hardware development, numerous efforts by using the Monte Carlo N-Particle Transport Code (MCNP) have been made on characterizations of neutron field near the LHD, neutron detector response, estimation of necessary time for in situ calibration of the NFM, etc. [47-51]. Note that the wide dynamic NFM had been employed in the TFTR [52] and the JT-60U [53], consisting of both functions of pulse counting and Campelling modes jointly. However, these systems are based on traditional analogue technology and are no longer commercially available at the present time. Therefore, we needed to develop a new system based on new technologies. Prior to the deuterium operation of the LHD, in situ calibration of the NFM was carried out from November 7 to 18,2016 using an intense ${ }^{252} \mathrm{Cf}$ spontaneous fission neutron source with radioactivity of about $800 \mathrm{MBq}[54,55]$ following the method standardized in Ref. 56. The operation range of ${ }^{235} \mathrm{UFC},{ }^{3} \mathrm{He}$ counter, and ${ }^{10} \mathrm{~B}$ counter on the LHD are shown in Fig. 3. It is seen that the FC line can cover $S_{n}$ over $10^{17} \mathrm{n} / \mathrm{s}$. Because the maximum $S_{n}$ in the LHD is expected to be $(1 \sim 2) \times 10^{16} \mathrm{n} / \mathrm{s}$, the NFM developed for the LHD can cover the entire region of the expected $S_{n}$. 
Neutron emission profile was measured with nuclear emulsion methods in the PLT for the first time in tori [57]. In the era of large tokamaks, neutron profile diagnostic has been regularly employed in the TFTR [5860], the JET [61, 62], and the JT-60U [63], providing valuable information on beam ion profile and/or radiation transport of beam ions due to magnetohydrodynamic (MHD) instabilities [64-66]. In the LHD, high-performance VNC of eleven channels was installed. The overview of the LHD-VNC is schematically drawn in Fig. 2(b). This is the first neutron camera in helical/stellarator devices in the world. The stilbene scintillation detector was chosen as a fast-neutron detector in terms of brightness and good neutron (n)gamma $(\gamma)$-ray discrimination capability through various detector tests at accelerator-type fusion neutron facilities. The LHD-VNC system is characterized by MHz range operation capability with automated $\mathrm{n}-\gamma$-ray discrimination function based on a leading-edge field-programmable gate array technology [67] and negligibly small cross talk fraction [51,68]. The neutron collimator is made of heavy concrete and is embedded in a hole in the concrete floor (2.0 m thick) of the torus hall. Radially aligned eleven stainless steel pipes $(1.5 \mathrm{~m}$ long $\times 3 \mathrm{~cm} \phi)$ are embedded in a heavy concrete as a path for birth neutrons. Detailed information of the LHD-VNC hardware are available in Refs. 68 and 69.

Triton burnup study is one of the primary physics subjects in the LHD deuterium project to demonstrate that confinement capability of energetic ion, in particular, $\mathrm{MeV}$ ion, is relevant to a fusion reactor plasma. The triton burnup ratio, which is defined as the ratio of secondary d-t neutron yield to primary d-d neutron yield, $Y_{D T} / Y_{D D}$ has been examined in tokamaks, e.g., the Frascati Tokamak [70, 71], the JET [72, 73], the TFTR [74], the Doublet III-D [75], the JT-60U [76, 77], and the Korea Superconducting Tokamak Advanced Research (KSTAR) [78]. In this work, initial study on triton behavior was performed by measuring $14 \mathrm{MeV}$ neutrons generated by secondary d-t reaction in a deuterium plasma with a neutron activation technique [79] and scintillating-fiber (Sci.-Fi.) detector [80-82]. In addition to these, neutron fluctuation detector (NFD) with a fast-neutron sensor consisting of $\mathrm{ZnS}: \mathrm{Ag}$ phosphor embedded in a hydrogenous polymer matrix is installed to measure fast-neutron fluctuation with high time resolution [83]. The LHD deuterium operation has begun with a comprehensive set of neutron diagnostics listed in Table 1 .

Table 1. A comprehensive set of neutron diagnostics prepared for the first deuterium campaign of the LHD

\begin{tabular}{|c|c|c|c|c|}
\hline System & Diagnostic & Detector & $\begin{array}{l}\text { Manufacturer (Model, Spec.) } \\
\text { or Originator } \\
\end{array}$ & Channel \\
\hline NFM & $\begin{array}{l}\text { Fusion output } \\
\text { Time resolved total neutron } \\
\text { emission rate }\end{array}$ & $\begin{array}{l}{ }^{235} \mathrm{U} \text { fission chamber } \\
{ }^{10} \mathrm{~B} \text { counter } \\
{ }^{3} \mathrm{He} \text { counter }\end{array}$ & $\begin{array}{l}\text { TETD }^{*}(\text { KSA-01, } 0.1 \mathrm{cps} / \mathrm{nv}) \\
\text { TETD* }^{*}(\text { E6863-558, } 6.5 \mathrm{cps} / \mathrm{nv}) \\
\text { TETD }^{*}(\text { E6862-500, } 30 \mathrm{cps} / \mathrm{nv})\end{array}$ & $\begin{array}{l}3 \\
1 \\
2\end{array}$ \\
\hline \multirow{2}{*}{ NAS } & $\begin{array}{l}\text { Shot-integrated DD neutron } \\
\text { yield }\end{array}$ & Indium disk & \multirow{2}{*}{ G-TECH $(10 \mathrm{~mm} \phi \times 1 \mathrm{~mm} \mathrm{t}$, purity $99.999 \%)$} & \multirow{2}{*}{2} \\
\hline & $\begin{array}{l}\text { Shot-integrated secondary DT } \\
\text { neutron yield }\end{array}$ & $\begin{array}{l}\text { Aluminum disk } \\
\text { Silicon disk } \\
\end{array}$ & & \\
\hline $\mathrm{VNC}$ & $\begin{array}{l}\text { Time-resolved DD neutron } \\
\text { profile }\end{array}$ & Stilbene scintillator & G-TECH $(20 \mathrm{~mm} \phi \times 10 \mathrm{~mm} \mathrm{t})$ & 11 \\
\hline NFD & DD neutron fluctuation & ZnS:Ag phosphor & G-TECH $($ EJ-410, $25 \mathrm{~mm} \phi \times 19 \mathrm{~mm} \mathrm{t})$ & 2 \\
\hline
\end{tabular}




\begin{tabular}{|c|c|c|c|c|}
\hline & & $\begin{array}{l}\text { embedded in a } \\
\text { hydrogenous polymer } \\
\text { matrix }\end{array}$ & & \\
\hline Sci.-Fi. & $\begin{array}{l}\text { Time resolved secondary DT } \\
\text { neutron flux }\end{array}$ & Scintillating fiber & $\begin{array}{l}\text { Los Alamos National Laboratory } \\
\text { National Institute for Fusion Science } \\
\text { National Institute of Technology, Toyama } \\
\text { College }\end{array}$ & 3 \\
\hline
\end{tabular}

*TETD : Toshiba Electron Tube Device Co. Ltd.

\section{Experimental results}

\subsection{Neutron emission rate and yield}

Neutrons resulting from d-d fusion reactions have been observed in LHD deuterium plasmas. The first deuterium plasma was successfully initiated by ECRH without NB injection in March 7, 2017. The discharge waveform of the first deuterium plasma is shown in Fig. 4. In this shot, neutrons were generated by thermonuclear reactions due to finite fuel ion temperature since energetic ion was not present because of ECRH plasmas, and $S_{n}$ was evaluated to be about $1 \times 10^{11} \mathrm{n} / \mathrm{s}$. As can be seen, the ${ }^{3} \mathrm{He}$ counter provides neutron pulse counting rate with good statistics because the sensitivity of ${ }^{3} \mathrm{He}$ counter to neutron is the highest among the three detectors whereas the FC signal is the weakest and is not effective for evaluating $S_{n}$ precisely. As for ECRH plasmas, a central fuel deuteron temperature was derived from $S_{n}$ measured with in situ calibrated NFM [84]. The analysis indicated that central fuel deuteron temperature ranged from $1 \mathrm{keV}$ to $1.5 \mathrm{keV}$ and was consistent with impurity ion temperature measured with spectroscopy.

The maximum $S_{n}$ shot was explored by injecting all five NBs with scanning electron density $\left(n_{e}\right)$ and magnetic configuration. The maximum $S_{n}$ shot was achieved in an inward shifted configuration $\left(R_{a x} / B_{t}\right.$ of $3.55 \mathrm{~m} / 2.87 \mathrm{~T}$ ) that provides the longest energy confinement time and good confinement property of helically trapped energetic ions. The discharge waveforms are displayed in Fig. 5. In this particular shot, $S_{n}$ reached $3.3 \times 10^{15} \mathrm{n} / \mathrm{s}$ with the help of fueling deuterium pellet injection which was the record value of $S_{n}$ in the first deuterium campaign of the LHD.

Next, $S_{n}$ was systematically examined to understand the parameter dependence of $S_{n}$ and to make a comparison with that predicted by simulations. Experimentally observed $S_{n}$ as a function of line-averaged $n_{e}$ is shown in Fig. $6 . S_{n}$ plotted in Fig. 6 is the peak value for each discharge and line-averaged $n_{e}$ is of the value when the maximum $S_{n}$ is recorded. As can be seen, $S_{n}$ increases as line-averaged $n_{e}$ increases in the low- $n_{e}$ region $\left(n_{e}<2 \times 10^{19} \mathrm{~m}^{-3}\right)$. This is due to increase of beam deposition, and then $S_{n}$ reaches the peak in around $n_{e}$ of $(2-3) \times 10^{19} \mathrm{~m}^{-3}$. $S_{n}$ starts to decrease as $n_{e}$ increases further because Spitzer slowing down time $\tau_{s}$ becomes shorter, and as a result, accumulation of beam ions is reduced in a plasma. This tendency agrees well with dependence of $S_{n}$ on $n_{e}$ predicted by the model based on velocity distribution function for beam ions described by the steady-state Fokker-Planck equation [30].

To confirm whether beam ions slow down classically without loss or not, deuterium beam blips were 
injected into ECRH plasmas. The beam blip method has been widely employed in an early phase of deuterium operation of several tokamaks and the Compact Helical System [10-12, 26, 27]. In this case, we injected beam ions perpendicularly by using P-NB\#4 since confinement characteristic of helically trapped energetic ions have been a great concern in helical devices. The plasma density was gradually varied in time in this shot to change $\tau_{s}$ for beam ions. As can be seen in Fig. 7, $S_{n}$ increases immediately right after NB turn-on, and starts to decrease after NB turn-off with a finite decay time. Our interest is in whether perpendicularly injected beam ions decelerate classically without loss or not. Next, time evolution of $S_{n}$ is calculated with the simple classical slowing-down model FBURN [85]. In this code, beam ions are assumed to be slowed down in each shell according to the classical energy loss theory based on Stix's formula [86]. The domain of plasma is divided into 120 circular shells and each volume is given according to the equilibrium reconstructed every $50 \mathrm{~ms}$ by VMEC2000 code [87]. Here, beam deposition profile is calculated using the HFREYA code [88]. Note that $\mathrm{d}-\mathrm{d}$ fusion reactivity between a plasma and a beam ion is given in Ref. 89. As can be seen in Fig. 7, the neutron decay rate following NB turn-off evaluated by the FBURN code agrees relatively well with experimentally measured neutron decay rate in line-averaged $n_{e}$ around $2 \times 10^{19} \mathrm{~m}^{-3}$. It tells us that perpendicularly injected beam ions decelerate classically without significant loss in this $n_{e}$ region. Note that there is a discrepancy between measured and calculated decays in lower $n_{e}\left(n_{e} \sim 1 \times 10^{19} \mathrm{~m}^{-3}\right)$ discharges characterized by a longer $\tau_{s}$ for beam ions, suggesting significant loss of perpendicularly injected beam ions in the low- $n_{e}$ regime.

\subsection{Neutron emission profile}

A radial profile of neutron emission rate is of inherent interest in nuclear fusion experiments. In the LHD, the line-integrated neutron emission profile has been successfully measured in the first deuterium campaign by using the VNC. At the beginning of commissioning phase, we performed $R_{a x}$ scanning experiments in the high field operation and verified the response of line-integrated neutron emission profile. The neutron emission profile was reasonably varied, i.e., the neutron profile shifted outwardly as the plasma column was shifted outwardly, and vice versa according to the $R_{a x}$ position [69]. Next, we measured neutron emission profiles in two different $B_{t}$ at the same $R_{a x}$ position. In this shot, N-NB\#1 and N-NB\#3 were tangentially coinjected with total $P_{N-N B}$ of $4 \mathrm{MW}$. Two radial profiles of line-integrated neutron pulse counting rate at the outboard side in $B_{t}$ of $1.375 \mathrm{~T}$ and $2.75 \mathrm{~T}$ at $R_{a x}$ of $3.6 \mathrm{~m}$ are shown in Fig. 8. The neutron pulse counting rate is centrally peaked in the case of $B_{t}$ of $2.75 \mathrm{~T}$ whereas the neutron profile is relatively flat in the case of $B_{t}$ of $1.375 \mathrm{~T}$. This is because drift surfaces of co-going beam ions largely deviate from magnetic flux surfaces to the outboard side of the plasma in $B_{t}$ of $1.375 \mathrm{~T}$ compared with the deviation of co-going beam ions in $B_{t}$ of $2.75 \mathrm{~T}$.

Two radial profiles of line-integrated neutron pulse counting rate with different injection angles of NB are shown in Fig. 9. One is the profile when the N-NB\#3 of which $E_{b}$ and $P_{N B}$ are $164 \mathrm{keV}$ and $1.8 \mathrm{MW}$, 
respectively, is tangentially co-injected. The other is the profile when the P-NB\#4 of which $E_{b}$ and $P_{N B}$ are $45 \mathrm{keV}$ and $4.3 \mathrm{MW}$, and the P-NB\#5 of which $E_{b}$ and $P_{N B}$ are $69 \mathrm{keV}$ and $6.7 \mathrm{MW}$, respectively, is perpendicularly injected. In both discharges, $n_{e}$ is set to be $\sim 2 \times 10^{19} \mathrm{~m}^{-3}$. As can be seen in Fig. 9, clear difference between the two neutron emission profiles can be recognized. In the case of tangential beam injection, the line-integrated neutron pulse counting rate is centrally peaked and decreases monotonically towards the peripheral domain. On the other hand, steep cliff can be recognized in the neutron emission profile in the case of perpendicular beam injection. This difference can be reasonably understood in the difference of orbit topologies in the Cartesian coordinates between co-going transit beam ions created by tangential NB injection and helically trapped beam ions generated by perpendicular NB injection [90].

Resistive interchange mode destabilized by helically trapped energetic ions often appear while two P-NBs are perpendicularly injected into relatively low- $n_{e}$ inward shifted plasma at high $B_{t}$. This mode occurs recurrently and is accompanied by a rapid frequency downshift. The mode is classified into energetic-particle continuum mode in the broad sense and is called energetic-ion-driven-interchange (EIC) mode [91,92]. Note that in the hydrogen experiment phase, observations related to radial transport and/or expulsion of beam ions were fairly limited. Only indirect observation such as rapid change of potential to negative, and increase of charge-exchanged fast neutrals was observed in the hydrogen phase. After the deuterium operation began, neutron signal became newly available, giving more direct information of global behavior of energetic ions while the EICs are excited. The NFM have indicated that effect of the EIC burst on $S_{n}$ is significant and $S_{n}$ largely drops due to the EIC burst, by about 50\% occasionally [93]. Fig. 10 shows change of neutron emission profile while the recurrent EIC modes are destabilized. In this shot, two perpendicular NBs are injected into the plasma with $n_{e}$ of $1.2 \times 10^{19} \mathrm{~m}^{-3}$. As can be seen, drop of line-integrated neutron pulse counting rate measured at the core channel is drastic whereas change of neutron emission rate is not visible in the peripheral chord. This observation tells us that helically-trapped beam ions are expelled due to the EICs since helicallytrapped beam ions are localized in a valley of two helical winding coils and confinement domain is just above the vicinity of central chord.

\subsection{Triton burnup}

The triton burnup experiment has been positioned as alpha particle simulation experiment in tokamaks. In deuterium plasmas of the LHD, secondary d-t neutron fluxes have been successfully measured by using the NAS and the Sci.-Fi. detector for the first time in helical/stellarator devices. Two time evolutions of $S_{n}$ measured with the NFM and secondary d-t neutron emission rate resulting from triton burnup evaluated with the Sci.-Fi. detector are shown in Fig.11. The Sci.-Fi. detector is calibrated through the NAS measurement. In this shot, three N-NBs are injected simultaneously into the plasma with $n_{e}$ of $1 \times 10^{19} \mathrm{~m}^{-3}$ at $R_{a x} / B_{t}$ of 3.6 $\mathrm{m} / 2.65 \mathrm{~T}$. It can be seen that the buildup of $14 \mathrm{MeV}$ neutron emission rate is slower than that of total neutron emission since the birth energy of triton is fairly high and it takes time to reach maximum d-t fusion reaction 
probability through their slowing down process. Two primary decay components are seen on the fission chamber signal after NBs are terminated. The second longer decay in the low neutron emissivity phase can be interpreted as the decay of triton burnup $14 \mathrm{MeV}$ neutron flux. The neutron decay rate provided by the Sci.-Fi. detector matches that measured with the NFM. It can be also seen in Fig. 11 that the triton burnup ratio, i.e. $Y_{D T} / Y_{D D}$ is lower than $1 \%$ in this shot. Our interest is in dependence of $Y_{D T} / Y_{D D}$ on magnetic field configuration since confinement of helically-trapped energetic ions is expected to be good in an inward shifted configuration because of so-called " $\sigma$-optimization" [94], whereas confinement of helically-trapped energetic ions is predicted to be poor in an outward shifted configuration [95]. Therefore, we performed $R_{a x}$ scanning experiment for triton burnup to verify the theoritical prediction. Experimentally evaluated $Y_{D T} / Y_{D D}$ as a function of $R_{a x}$ is shown in Fig. 12. Data points taken in $n_{e}$ range from $1 \times 10^{19} \mathrm{~m}^{-3}$ to $5 \times 10^{19} \mathrm{~m}^{-3}$ are plotted. The inward shifted configuration at $R_{a x} / B_{t}$ of $3.55 \mathrm{~m} / 2.89 \mathrm{~T}$ gives the highest $Y_{D T} / Y_{D D}$ of $\sim 0.45 \%$ and $Y_{D T} / Y_{D D}$ decreases as a plasma column is shifted outwardly as expected in Ref. 95. The highest value of $Y_{D T} / Y_{D D}$ recorded in the first deuterium campaign of the LHD is almost the same as that obtained in tokamak having a minor radius similar to that of the LHD. In the case of half $B_{t}, Y_{D T} / Y_{D D}$ is significantly reduced as seen in Fig.12. This is probably due to effects of larger Larmour radii of energetic tritons and significant deviation of triton's orbit from magnetic flux surfaces. Prior to the deuterium experiment, confinement property of $1 \mathrm{MeV}$ tritons was investigated by using the Global NEoclassical Transport (GNET) code. The GNET code suggests that particle and/or energy loss fraction in the inward shifted configuration is lower than that in the outward shifted configuration [96]. The tendency of measured $Y_{D T} / Y_{D D}$ on $R_{a x}$ position is consistent with that predicted by the GNET code in terms of the particle and/or energy loss fraction. Further detailed calculation on the triton burnup is being performed by using the GNET code to predict the magnetic configuration and plasma parameters that can potentially provide the highest $Y_{D T} / Y_{D D}$ in LHD deuterium plasmas.

\section{Summary}

The LHD project has stepped into a new stage. The first deuterium plasma was obtained in March 7, 2017, after long-term preparation to execute the deuterium operation. A comprehensive set of neutron diagnostics has been installed onto the LHD to extend energetic-particle physics studies in the LHD plasma characterized by three-dimensional magnetic configuration. The NFM on the LHD is based on leading-edge digital technologies, providing the maximum neutron pulse counting rate up to $5 \times 10^{9} \mathrm{cps}$. Prior to the deuterium operation, in situ calibration of the NFM was performed by using an intense ${ }^{252} \mathrm{Cf}$ of $\sim 800 \mathrm{MBq}$. In the first deuterium campaign, $S_{n}$ reached $3.3 \times 10^{15} \mathrm{n} / \mathrm{s}$ in the inwardly shifted configuration at $R_{a x}$ of $3.55 \mathrm{~m}$. The dependence of $S_{n}$ on $n_{e}$ is consistent with that predicted by the simple model calculation. Perpendicular beam blip experiments suggest that confinement of helically trapped beam ions can be explained by the classical slowing down model in high $n_{e}\left(>\sim 2 \times 10^{19} \mathrm{~m}^{-3}\right)$ range, whereas loss of helically-trapped beam ions is visible 
in low $n_{e}\left(\sim 1 \times 10^{19} \mathrm{~m}^{-3}\right)$ range. The radial profile of DD neutron emission rate has been measured with the wide dynamic range VNC equipped with online $n-\gamma$ discrimination capability for the first time in helical/stellarator devices. The line-integrated neutron emission profile has reasonably changed according to $R_{a x}$ position. Correlated with the EIC burst, significant drop of neutron counting rate in the vicinity of central chord was observed, suggesting expulsion of helically-trapped beam ions due to the EIC. We also performed triton burnup study through secondary d-t neutron measurement by using the NAS and the Sci.-Fi. detector. The maximum triton burnup rate in the first deuterium campaign was $\sim 0.45 \%$ and was recorded in the inward shifted plasma. The burnup ratio decreases as a plasma column is shifted outwardly, as expected.

\section{Acknowledgments}

The authors wish to thank the Director General of the National Institute of Fusion Science Professor Yasuhiko Takeiri for his continuous encouragement to realize the LHD deuterium experiment. The authors also wish to thank the LHD deuterium experiment preparation group for the enormous effort and great work done in realizing the deuterium experiment. The continuous effort by the LHD-NBI team for optimizing the NBI operation in deuterium is greatly acknowledged. This work is supported by the LHD project budgets ULGG801, ULHH003, and ULHH034.

\section{References}

[1] Lehner G, and Pohl F. 1967 Z. Physik 20783.

[2] Brysk H. 1973 Plasma Physics 15611.

[3] Bol K. et al 1974 Phys. Rev. Lett. 32661.

[4] EQUIPE TFR 1976 Nucl. Fusion 16279.

[5] Fisher W.A., Chen S.H., Gwinn D., and Parker R.R. 1983 Phys. Rev. A 283121.

[6] Jarvis O.N., Gorini G., Hone M., Källne J., Sadler G., Merlo V., van Belle P. 1986 Rev. Sci. Instrum. 57 1717.

[7] Jassby D.L. 1975 Phys. Lett. 55A 225.

[8] Jassby D.L. 1977 Nucl. Fusion 17309.

[9] Strachan J.D et al 1981 Nucl. Fusion 2167.

[10] Heidbrink W.W. Kim Jinchoon, and Groebner R.J. 1988 Nucl. Fusion 281897.

[11] Heidbrink W.W. et al 1990 Phys. Fluids B 33167.

[12] Tobita K., Tani K., Nishitani T., Nagashima K., and Kusama Y. 1994 Nucl. Fusion 341097.

[13] McGuire K. et al 1983 Phys. Rev. Lett. 50891.

[14] Sadler G.J., Conroy S.W., Jarvis O.N., Adams J.M., and Hone M.A. 1990 Fusion Technol. 18556.

[15] Heibrink W.W. and Sadler G.J. 1994 Nucl. Fusion 34535.

[16] Jarvis O.N. 1994 Plasma Phys. Control. Fusion 36209. 
[17] Wolle B. 1999 Phys. Rep. 3121.

[18] Kiptily V.G., Cecil F.E., and Medley S.S. 2006 Plasma Phys. Control. Fusion 48 R59.

[19] Krasilnikov A.V et al 2005 Nuclear Fusion 451503.

[20] Sasao M., Nishitani T., Krasilnikov A., Popovichev S., Kiptily V.G., and Källne J. 2008 Fus. Sci. Technol. 53604.

[21] Bertalot L. et al 2012 JINST 7 C04012.

[22] Weller A., and Maaßberg 1985 Report No. IPP 2/278, Max-Planck-Institut für Plasmaphysik.

[23] Besshou S., Motojima O., Sato M., Sano F., Obiki T., Iiyoshi A., and Uo K. 1985 Nucl. Instrum. Meth. A237 590 .

[24] Iki E. et al 1997 Fus. Eng. Des. 34-35 603.

[25] Wade M.R., Thomas C.E., Colchin R.J., Rome J.A., England A.C., Fowler R.H. 1995 Nucl. Fusion 35 1029 .

[26] Isobe M., Sasao M., Osakabe M., Fujita J., Okamura S., Kumazawa R., Minami T., Matsuoka K., and Takahashi C. 1997 Rev. Sci. Instrum. 68532.

[27] Isobe M., Sasao M., Okamura S., Osakabe M., Kubo S., Minami T., Matsuoka K., Takahashi C., and CHS Group 1998 J. Plasma Fusion Res. SERIES 1366.

[28] Wolle B., Weller A., Schill S., Gadelmeier F., Baloui T., and Beikert G. 1999 Rev. Sci. Instrum. 701197.

[29] Rust N., Reimbold S., Hübner K., Gadelmeier F., Penningsfeld F.P., and Weller A. $200027^{\text {th }}$ EPS Conference on Contr. Fusion and Plasma Phys. Budapest, 12-16 June 2000 ECA Vol. 24B 1621.

[30] Osakabe M. et al 2017 Fus. Sci. Technol. 72199.

[31] Saida T. et al 2004 Nucl. Fusion 44488.

[32] Osakabe M. et al 2010 Fus. Sci. Technol. 58131.

[33] Ogawa K. et al 2012 Plasma Fus. Res. 72402014.

[34] Ogawa K. et al 2012 Nucl. Fusion 52094013.

[35] Ogawa K. et al 2012 Plasma Sci. Technol. 14269.

[36] Ogawa K. et al 2013 Nucl. Fusion 53053012.

[37] Isobe M, Ogawa K., Toi K., Osakabe M., Nagaoka K., Shimizu A., Spong D.A., Okamura S., CHS, and LHD Experiment Group 2010 Contrib. Plasma Phys. 50540.

[38] Ogawa K., Isobe M., Toi K., Watanabe F., Spong D.A., Shimizu A., Osakabe M., Ohdachi S., Sakakibara S., and LHD Experiment Group 2010 Nucl. Fusion 50084005.

[39] Ogawa K., Isobe M., Toi K., Shimizu A., Osakabe M., and LHD Experiment Group 2014 Plasma Fus. Res. 93402097.

[40] Isobe M. et al 2010 Fus. Sci. Technol. 58426.

[41] Takeiri Y. et al 2017 Nucl. Fusion 57102023.

[42] Jassby D.L. et al 1991 Phys. Fluids B 32308. 
[43] Nishitani T. et al 1994 Nucl. Fusion 341069.

[44] Sasao M., Isobe M., Osakabe M., Taniike A., Iguchi T., Takada E., Iida T., and Wada M. 1997 Fus. Eng. Des. 34-35 595.

[45] Isobe M. et al 2010 Rev. Sci. Instrum. 81 10D310.

[46] Isobe M. et al 2014 Rev. Sci. Instrum. 85 11E114.

[47] Nishio N., Yamamoto S., Watanabe K., Uritani A., Isobe M., and Yamanishi H. 2010 Rev. Sci. Instrum. 81 10D306.

[48] Nishio N., Yamazaki A., Watanabe K., Uritani A., Isobe M., and Yamanishi H. 2011 Plasma Fus. Res. 6 2405115.

[49] Nakano Y., Yamazaki A., Watanabe K., Uritani A., Ogawa K., and Isobe M. 2014 Rev. Sci. Instrum. 85 $11 \mathrm{E} 116$.

[50] Nakano Y., Yamazaki A., Watanabe K., Uritani A., Ogawa K., and Isobe M. 2014 Plasma Fus. Res. 9 3405141.

[51] Nishitani T., Ogawa K., and Isobe M. 2017 Fus. Eng. Des. 1231020.

[52] England A.C., Hendel H.W., and Nieschmidt E.B 1986 Rev. Sci. Instrum. 571754.

[53] Nishitani T. 1992 Kakuyugo kenkyu 686 (in Japanese).

[54] Isobe M. et al submitted to IEEE Transactions on Plasma Science.

[55] Nishitani T. et al 2018 Fus. Eng. Des. in press.

[56] Strachan J.D. et al 1990 Rev. Sci. Instrum. 613501.

[57] Strachan J.D. Bhattacharjee A., Jassby D.L., and Towner H.H. 1978 Phys. Lett. 66A 295.

[58] Hendel H.W., Ku L.P., Long D.C., Nieschmidt E.B., Strachan J.D. 1985 Rev. Sci. Instrum. 561081.

[59] Roquemore A.L., Chouinard R.C., Diesso M., Palladino R., Strachan J.D. 1990 Rev. Sci. Instrum. 61 3163.

[60] Johnson L.C. 1992 Rev. Sci. Instrum. 634517.

[61] Adams J.M., Jarvis O.N., Sadler G.J., Syme D.B., and Watkins N. 1993 Nucl. Instrum. Meth. A 329277.

[62] Jarvis O.N., Adams J.M., Marcus F.B., and Sadler G.J. 1997 Fus. Eng. Des. 34-35 59.

[63] Ishikawa M., Nishitani T., Morioka M., Takechi M., Shinohara K., Shimada M., Miura Y., Nagami M., Kaschuk Yu. A. 2002 Rev. Sci. Instrum. 734237.

[64] Marcus F.B., Adams J.M., Bond D.S., Hone M.A., Howatrh P.J.A., Jarvis O.N., Loughlin M.J., Sadler G.J., van Belle P., and Watkins N. 1994 Nucl. Fusion 34687.

[65] Roquemore A.L., Bitter M., Johnson L.C., and von Goeler S. 1997 Rev. Sci. Instrum. 68544.

[66] Ishikawa M. et al 2007 Nucl. Fusion 47849.

[67] Ogawa K., Isobe M., Takada E., Uchida Y., Ochiai K., Tomita H., Uritani A., Kobuchi T., and Takeiri Y. 2014 Rev. Sci. Instrum. 85 11E110.

[68] Kawase H., Ogawa K., Nishitani T., Pu N., and Isobe M. submitted to IEEE Transactions on Plasma 
Science.

[69] Kawase H., Ogawa K., Nishitani T., Pu N., Murakami S., and Isobe M. submitted to Plasma Fusion Research.

[70] Batistoni P., Martone M., Pillon M., Podda S., Rapisarda M. 1987 Nucl. Fusion 271040.

[71] Pillon M., and Vannucci A. 1987 Nucl. Instrum. Meth. A 255188.

[72] Conroy S., Jarvis O.N., Sadler G., Huxtable G.B. 1988 Nucl. Fusion 282127.

[73] Nemtsev G., Amosov V., Meshchaninov S., Popovichev S., Rodionov R., and JET Contributors 2016 Rev. Sci. Instrum. 87 11D835.

[74] Barnes C.W. et al 1998 Nucl. Fusion 38597.

[75] Duong H.H., and Heidrink W.W. 1993 Nucl. Fusion 33211.

[76] Nishitani T., Hoek M., Harano H., Isobe M., Tobita K., Kusama Y., Wurden G.A., and Chrien R.E 1996 Plasma Phys. Control. Fusion 38355.

[77] Hoek M., Nishitani T. Carlsson M., and Carlsson T. 1996 Nucl. Instrum. Meth. A 368804.

[78] Jo Jungmin, Cheon MunSeong, Kim Jun Young, Rhee T., Kim Junghee, Shi Yue-Jiang, Isobe M., Ogawa K., Chung Kyoung-Jae, Hwang Y.S. 2106 Rev. Sci. Instrum. 8711 D828.

[79] Pu N., Nishitani T., Isobe M., Ogawa K., Kawase H., Tanaka T., Li S.Y., Yoshihashi Y., and Uritani A. 2017 Rev. Sci. Instrum. 88113302.

[80] Wurden G.A., Chrien R.E., Barnes Cris W., Sailor W.C., Roquemore A.L., Lavelle M.J., O’Gara P.M., and Jordan R.J. 1995 Rev. Sci. Instrum. 66901.

[81] Sailor W.C., Barnes Cris W., Chrien R.E., and Wurden G.A. 1995 Rev. Sci. Instrum. 66898.

[82] Nishitani T., Hoek M., Harano H., Isobe M., Tobita K., Kusama Y., Wurden G.A., and Chrien R.E. 1996 Plasma Phys. Control. Fusion 38355.

[83] Ogawa K., Isobe M., Kawase H., Nishitani T., Pu. N., and LHD Experiment Group submitted to Plasma and Fusion Research.

[84] Ogawa K., Isobe M., Nishitani T., Kawase H., Pu N., and LHD Experiment Group 2017 Plasma and Fus. Res. 121202036.

[85] Ogawa K., Isobe M., Nishitani T., Murakami S., Seki R., Nakata M., Takada E., Kawse H., Pu N., and LHD Experiment Group 2108 Nuclear Fusion 58034002.

[86] Batistoni P., and Barnes C.W. 1991 Plasma Phys. Control. Fusion 331735.

[87] Hirshman S. P., and Betancourt O. 1991 J. Comput. Phys. 9699.

[88] Murakami S., Nakajima N., and Okamoto M. 1995 Trans. Fusion Technol. 27256.

[89] Mikkelsen D.R. 1989 Nucl. Fusion 291113.

[90] Watanabe T. et al 2006 Nucl. Fusion 46291.

[91] Du X.D. et al 2015 Phys. Rev. Lett. 114155003.

[92] Du X.D. et al 2016 Nucl. Fusion 56016002. 
[93] Bando T. et al "Excitation of helically-trapped-energetic-ion driven resistive interchange modes with intense deuterium beam injection and enhanced effect on beam ions/bulk plasmas of LHD", submitted to Nucl. Fusion.

[94] Mynick H.E., Chu T.K., and Boozer A.H. 1982 Phys. Rev. Lett. 48322.

[95] Murakami S. et al 2002 J. Plasma Fusion Res. SERIES 5620.

[96] Homma M., Murakami S., Isobe M., Tomita H., and Ogawa K. 2015 Plasma and Fus. Res. 103403050. 


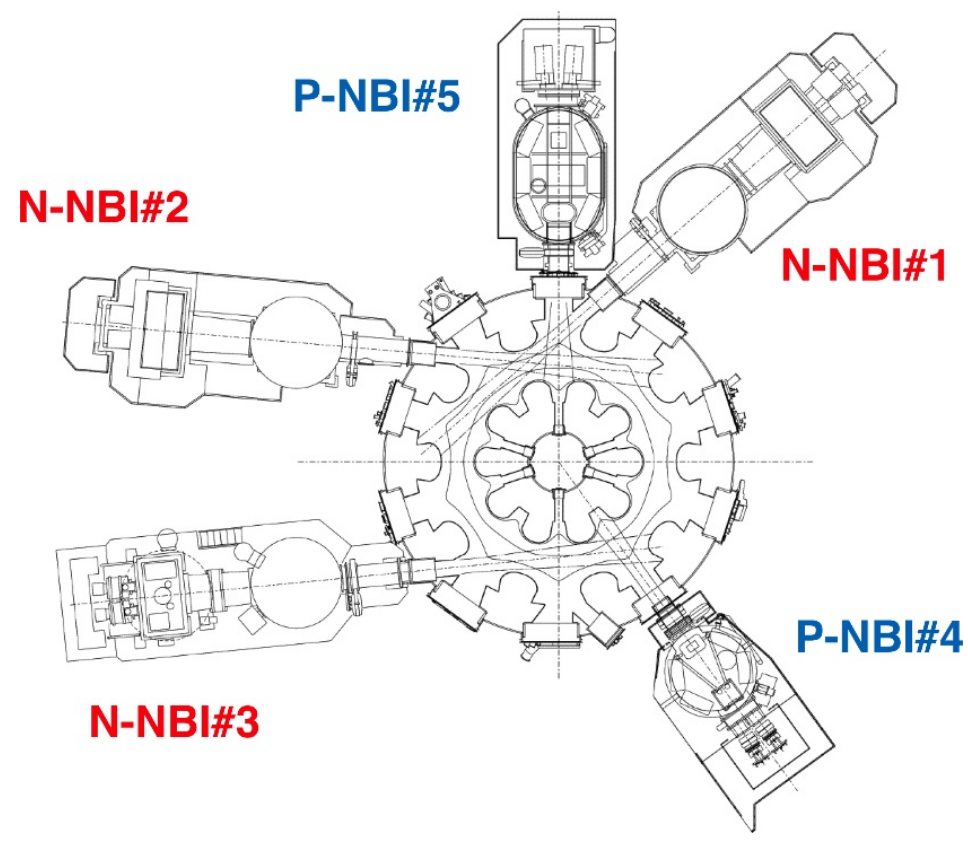

Fig. 1 Arrangement of five neutral beam injectors on the LHD. The N-NBI represents negative-ion-sourcebased neutral beam injector with $E_{b}$ of $180 \mathrm{keV}$. The P-NBI stands for positive-ion-source-based neutral beam injector with $E_{b}$ of $60 \mathrm{keV}$ to $80 \mathrm{keV}$.
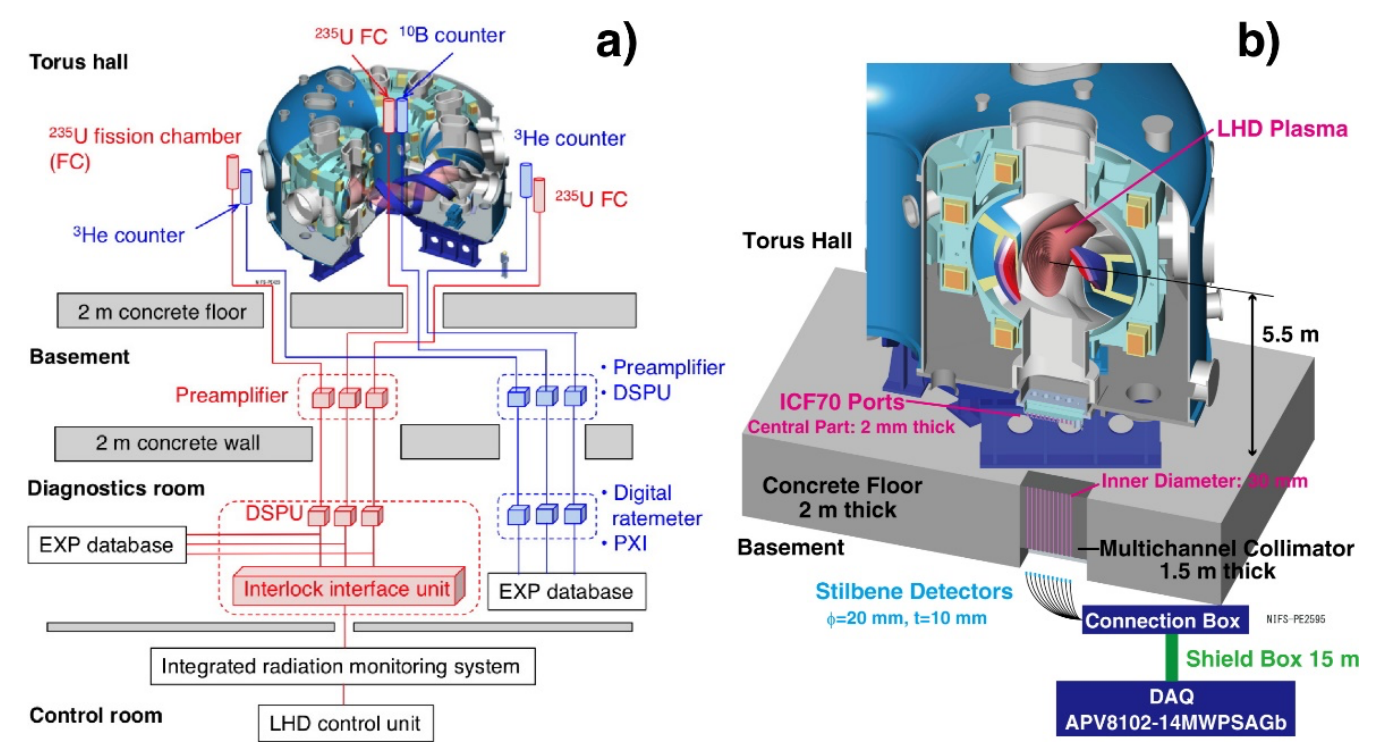

Fig. 2 Primary neutron diagnostic system on the LHD. a) wide dynamic range neutron flux monitor having fast time response, and b) vertical neutron camera capable of operating in $\mathrm{MHz}$ range with automated neutron and gamma-ray discrimination capability. In addition to these, neutron activation system having two irradiation ends at vertically and horizontally elongated poloidal cross sections, neutron fluctuation detectors, and scintillating-fiber detectors for triton burnup study are installed. 


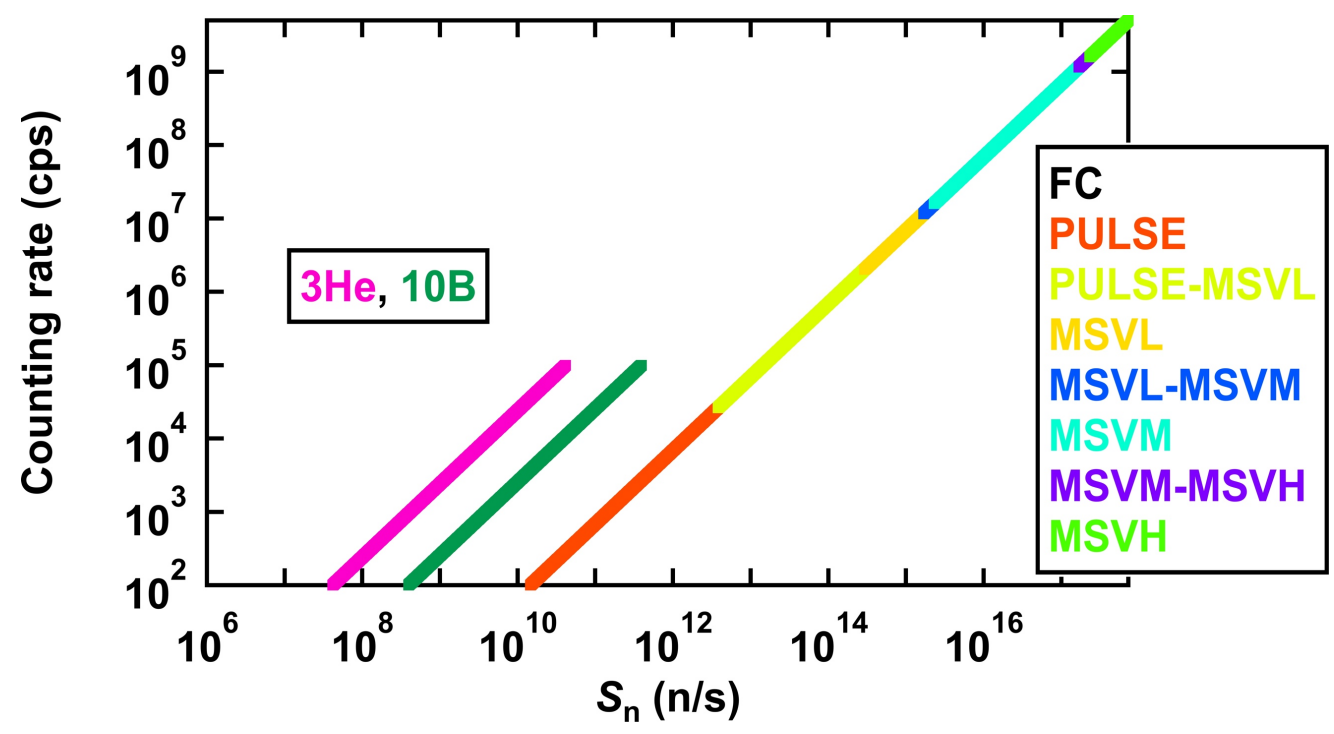

Fig. 3 Operation range of ${ }^{235} \mathrm{U}$ fission chamber, ${ }^{3} \mathrm{He}$ counter, and ${ }^{10} \mathrm{~B}$ counter on the LHD. Here, MSVL, MSVM, and MSVH represent mean square root voltage (MSV) for low neutron rate, middle neutron rate, and high neutron rate ranges, respectively. The operation range overlapped by two neighboring modes is described by using “-”.

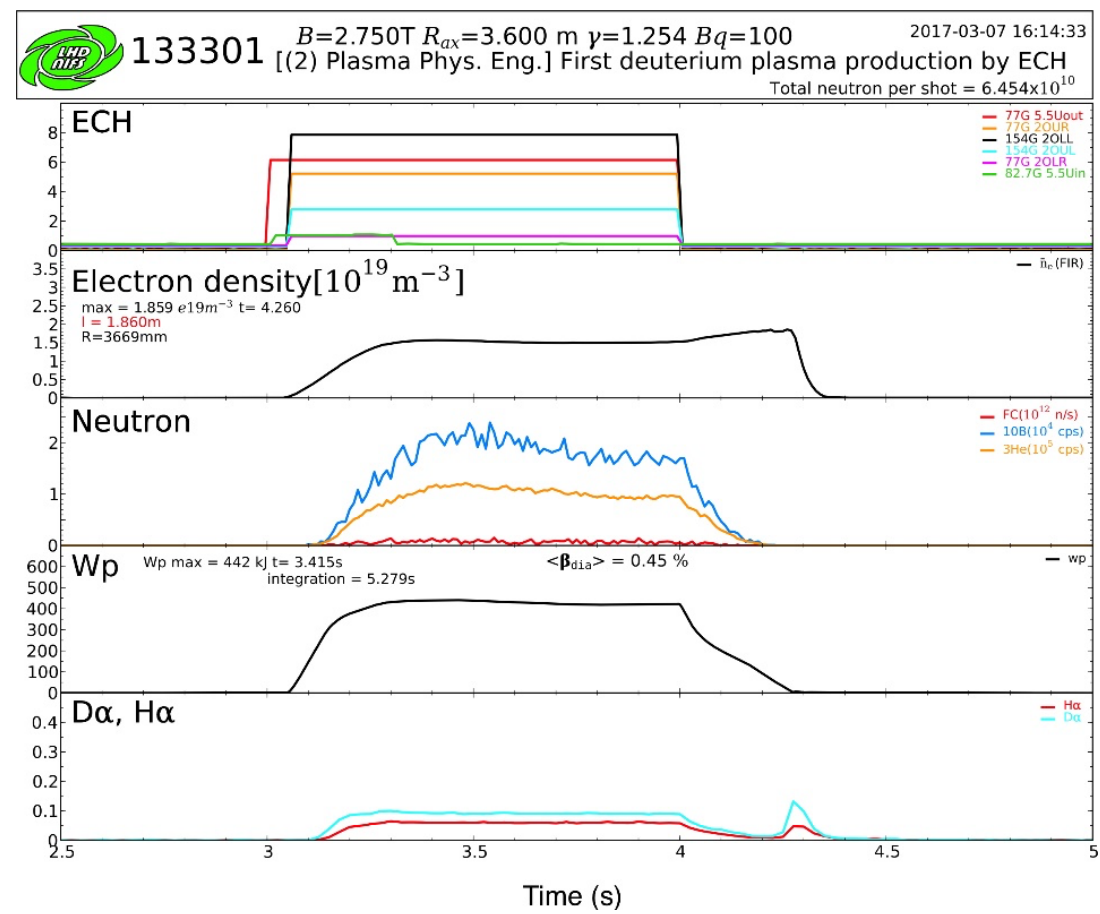

Fig. 4 Waveforms of first deuterium plasma of the LHD. The plasma was initiated and sustained by ECRH with $P_{E C R H}$ of $4.8 \mathrm{MW}$. 


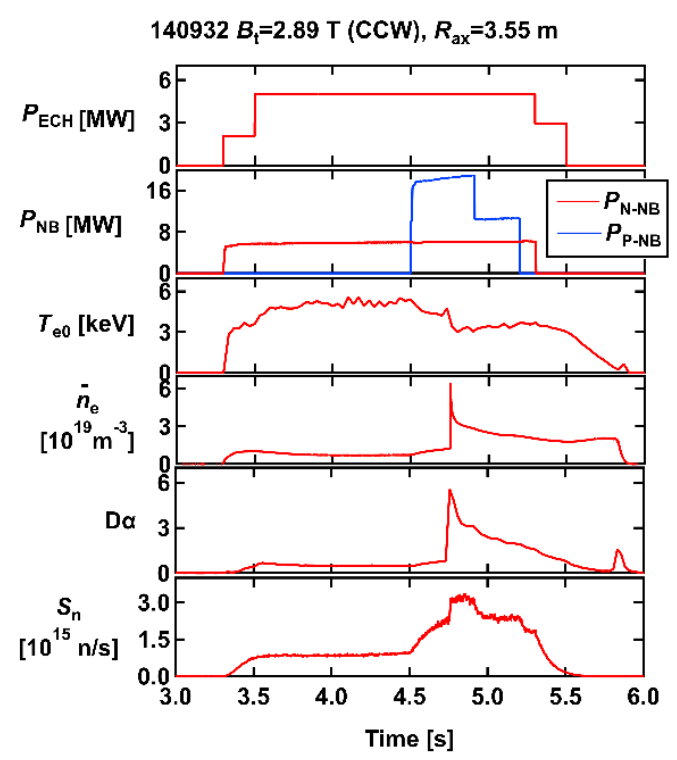

Fig. 5 Waveforms of the discharge where the maximum total neutron emission rate was recorded in the first deuterium campaign of the LHD. The total neutron emission rate reached $3.3 \times 10^{15} \mathrm{n} / \mathrm{s}$ in this shot. $P_{N-N B}$ and $P_{P-N B}$ were $5.9 \mathrm{MW}$ and $19 \mathrm{MW}$, respectively.

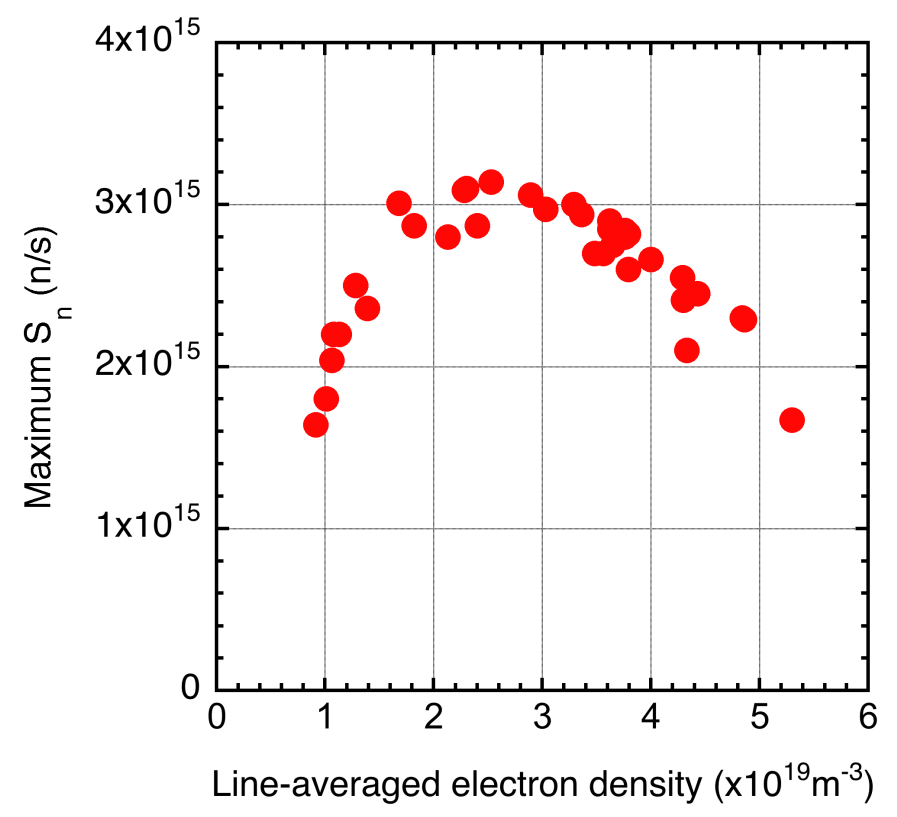

Fig. 6 Maximum total neutron emission rate as a function of line-averaged electron density in $R_{a x} / B_{t}$ of 3.55 $\mathrm{m} / 2.89$ T. $P_{N-N B}$ and $P_{P-N B}$ were about $6 \mathrm{MW}$ and $18 \mathrm{MW}$, respectively. 


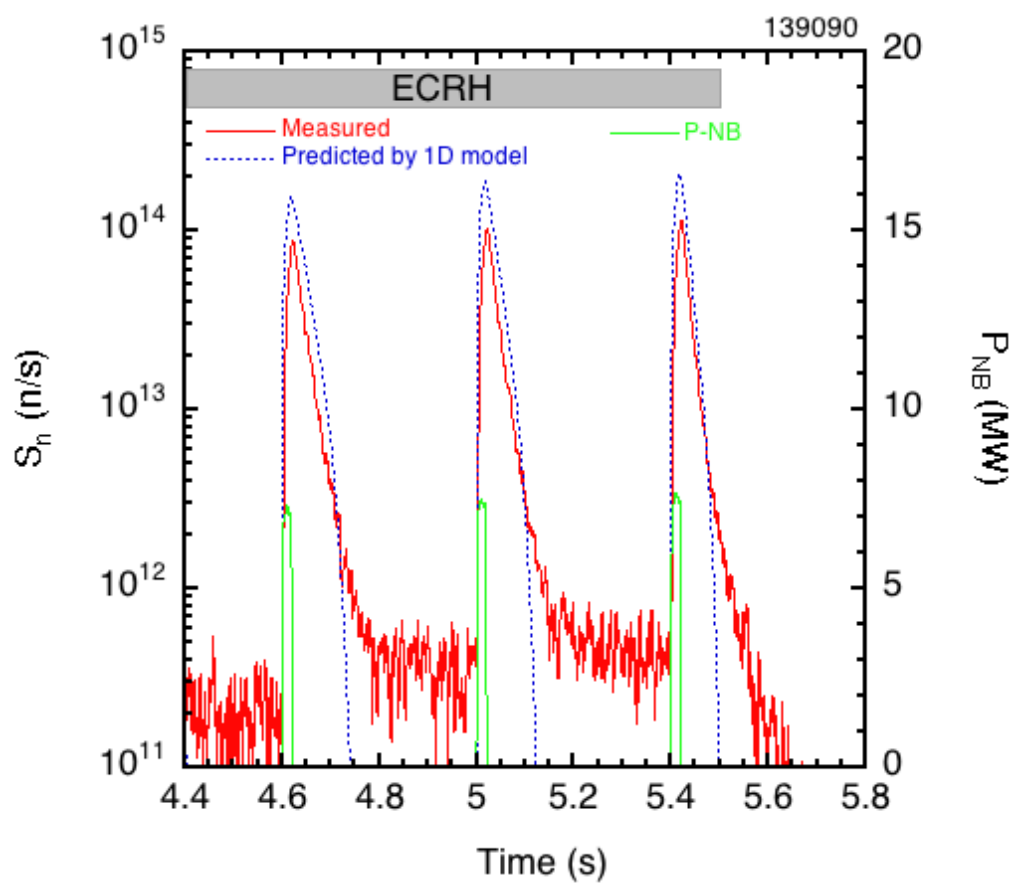

Fig. 7 Time evolutions of discharge when perpendicular beam blip is injected by using P-NB\#4 $\left(P_{P-N B^{\sim}} 7\right.$ $\mathrm{MW})$ into ECRH $\left(P_{E C R H^{\sim}} 2.5 \mathrm{MW}\right)$-sustained plasma. Line-averaged $n_{e}$ is gradually increased from lineaveraged $n_{e}$ of $1.5 \times 10^{19} \mathrm{~m}^{-3}$ at $t=4.4 \mathrm{~s}$ to line-averaged $n_{e}$ of $2.7 \times 10^{19} \mathrm{~m}^{-3}$ at $t=5.4 \mathrm{~s}$.

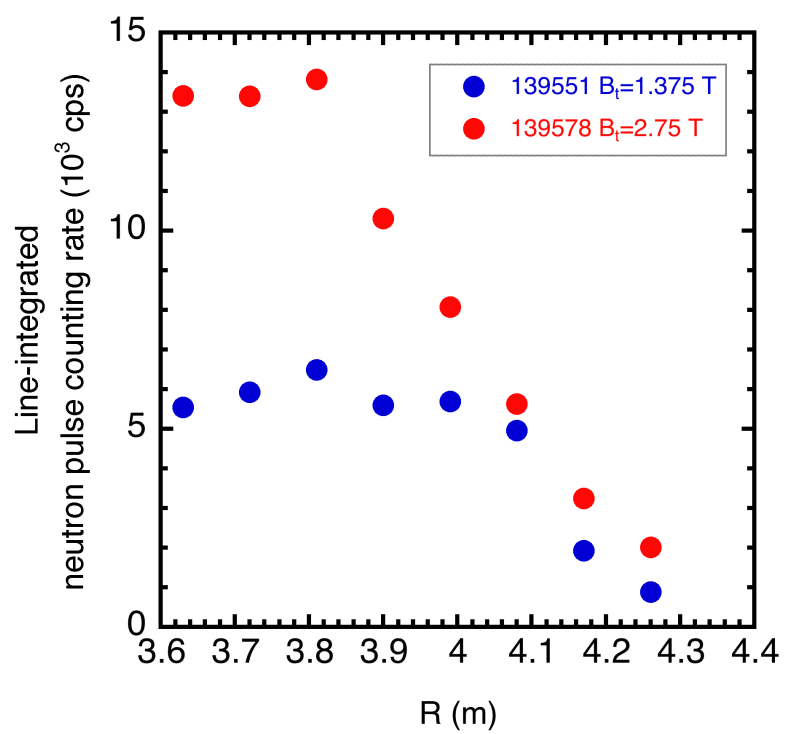

Fig. 8 Two radial profiles of line-integrated neutron pulse counting rates in the two different $B_{t}$, i.e., $1.375 \mathrm{~T}$ and $2.75 \mathrm{~T}$ at $R_{a x}$ of $3.6 \mathrm{~m}$ when two neutral beams, i.e. N-NB\#1 and \#3 are tangentially coinjected into the plasma of line-averaged $n_{e}=2 \times 10^{19} \mathrm{~m}^{-3}$. 

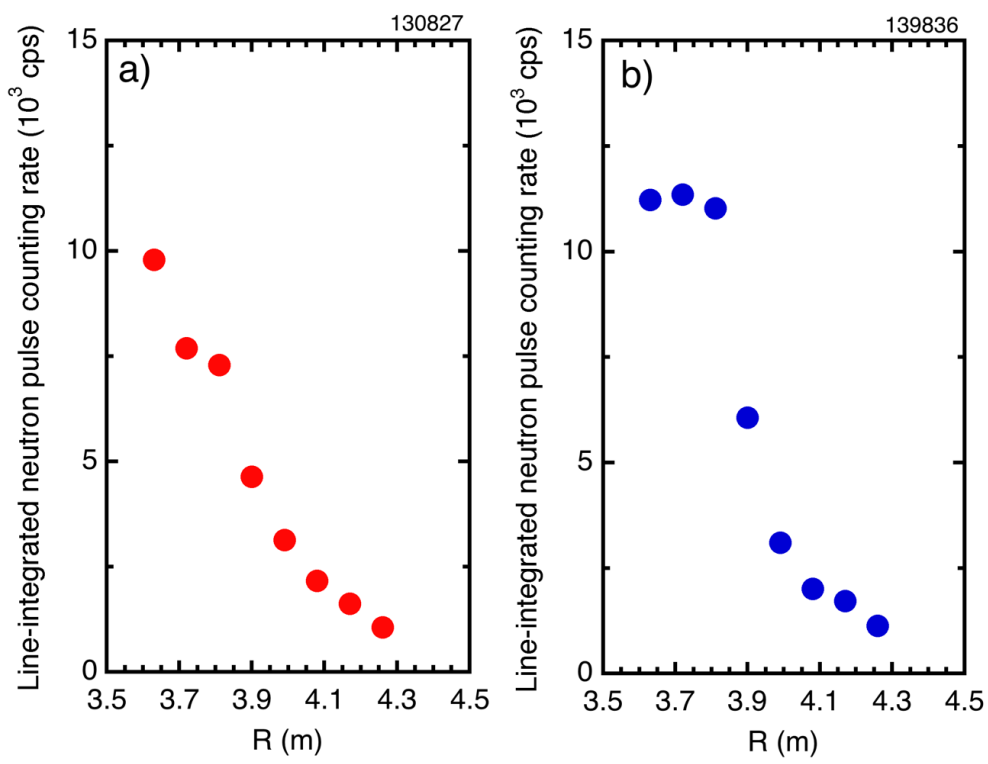

Fig. 9 Radial profiles of line-integrated neutron pulse counting rate. a) profile when N-NB\#3 ( $P_{N-N B}=1.8$ MW) is tangentially injected in $R_{a x} / B_{t}$ of $3.55 \mathrm{~m} / 2.78 \mathrm{~T}$, b) profile when P-NB\#4 ( $\left.P_{P-N B}=4.3 \mathrm{MW}\right)$ and PNB\#5 $\left(P_{P-N B}=6.7 \mathrm{MW}\right)$ are perpendicularly injected in $R_{a x} / B_{t}$ of $3.6 \mathrm{~m} / 2.75 \mathrm{~T}$. Line-averaged $n_{e}$ is set to be $\sim 2 \times 10^{19} \mathrm{~m}^{-3}$ for both discharges.

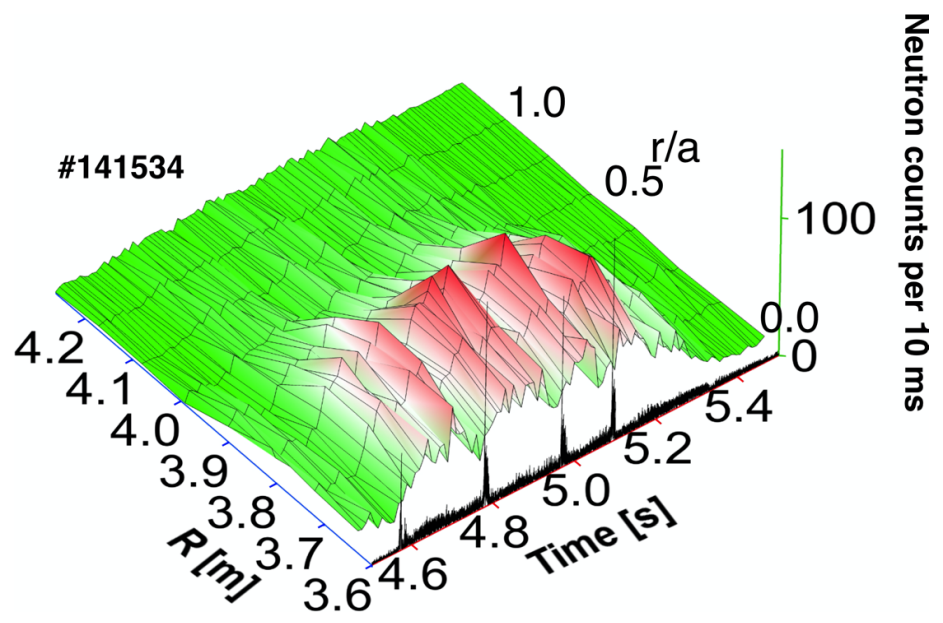

Fig. 10 Significant change of neutron emission profile while MHD instabilities driven by helically trapped energetic beam ions are delivered by perpendicular P-NB\#4 and \#5 in $R_{a x} / B_{t}$ of $3.6 \mathrm{~m} / 2.75$ T. Line-averaged $n_{e}$ was $1.2 \times 10^{19} \mathrm{~m}^{-3}$ in this shot. Here, black solid line represents time evolution of amplitude of MHD bursts in arbitrary unit. 


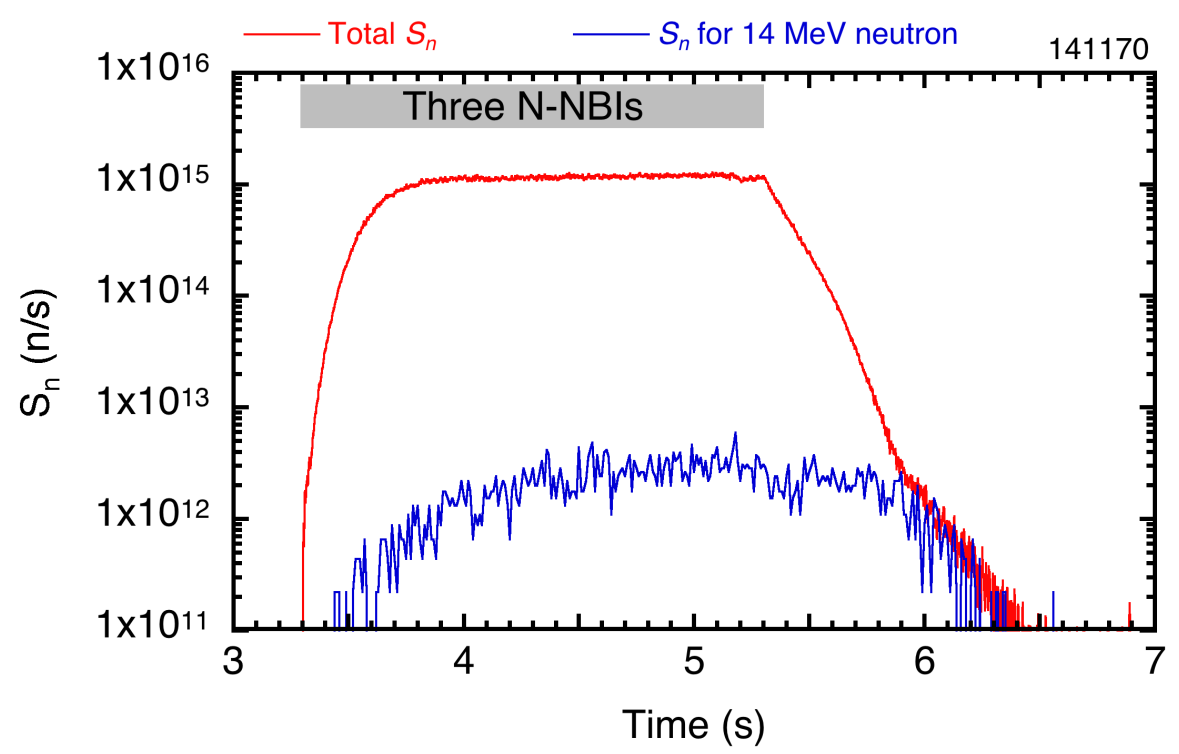

Fig. 11 Time evolutions of total neutron emission rates measured with the NFM and secondary d-t neutron emission rate evaluated with the Sci.-Fi. detector calibrated by the NAS. Total $P_{\mathrm{N}-\mathrm{NB}}$ is $5.8 \mathrm{MW}$, and lineaveraged $n_{\mathrm{e}}$ is about $1 \times 10^{19} \mathrm{~m}^{-3}$ in this shot.

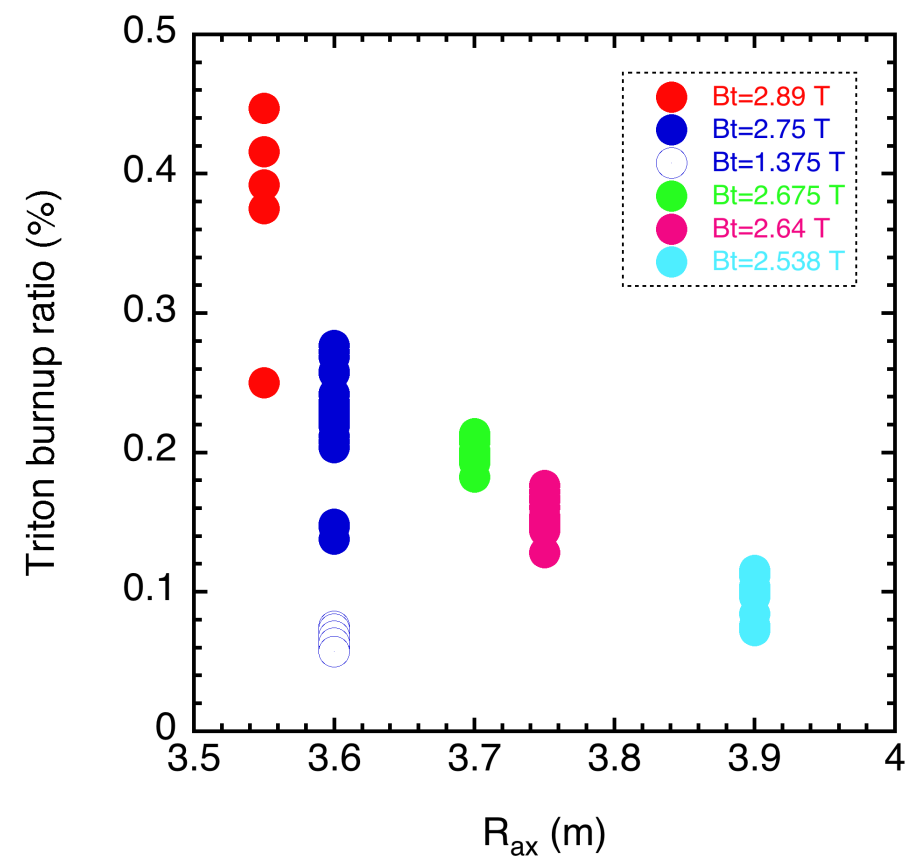

Fig. 12 Dependence of triton burnup ratio on magnetic field configuration in the LHD. Line-averaged $n_{e}$ ranges from $1 \times 10^{19} \mathrm{~m}^{-3}$ to $4 \times 10^{19} \mathrm{~m}^{-3}$. Full power NB heating is performed in these shots. 